\title{
Protein-Energy Malnutrition Increases Mortality in Patients Hospitalized With Bacterial Pneumonia: A Retrospective Nationwide Database Analysis
}

\author{
Sriram Gonakoti ${ }^{1}$, Iyobosa F. Osifo ${ }^{2}$ \\ 1. Internal Medicine, John H. Stroger, Jr. Hospital of Cook County, Chicago, USA 2. Medicine, Aminu Kano Teaching \\ Hospital, Kano, NGA
}

Corresponding author: Iyobosa F. Osifo, iyobosa.osifo@gmail.com

\section{Abstract \\ Background}

Malnutrition is a less commonly recognized risk factor for various infections. It encompasses both undernutrition or protein-energy malnutrition (PEM) and overnutrition, including obesity. This study aimed to evaluate whether PEM impacts bacterial pneumonia (BP) and, if so, to quantify the degree of impact on inpatient outcomes.

\section{Methods}

This was a retrospective cohort study involving adult hospitalizations for BP using the nationwide inpatient database. Outcomes included comparing inpatient mortality, total hospital charges, length of hospital stay, as well as complications from bacterial pneumonia.

\section{Results}

The in-hospital mortality for adults with BP was $2.62 \%$. Patients with PEM had a higher adjusted odds ratio (aOR) of inpatient mortality (adjusted odds ratio (aOR): 2.31, 95\% confidence interval (CI): $2.14-2.48$, $\mathrm{p}<0.001$ ) as compared to non-PEM patients. PEM was also associated with higher odds of sepsis (aOR: 2.24 , 95\% CI: 2.04 - 2.46, p<0.001), septic shock (aOR: 3.29, 95\% CI: 2.82 - 3.85, p<0.001), requiring mechanical ventilation (aOR: $2.51,95 \%$ CI: 2.31 - 2.71, $\mathrm{p}<0.001$ ), requiring vasopressors (aOR: 2.90, 95\% CI: 2.20 - 3.83, $\mathrm{p}<0.001$ ), acute respiratory distress syndrome (ARDS) (aOR: 1.63, 95\% CI: $1.33-2.00, \mathrm{p}<0.001$ ), acute kidney failure (AKI) (aOR: 1.24, 95\% CI: 1.18 - 1.29, p<0.001), deep vein thrombosis (DVT) (aOR: 1.80, 95\% CI: 1.62 $2.00, \mathrm{p}<0.001$ ), and pulmonary embolism (PE) (aOR: $1.25,95 \%$ CI: $1.08-1.45, \mathrm{p}=0.003)$.

\section{Conclusion}

Review began $12 / 22 / 2020$ Review ended 01/09/2021 Published 01/12/2021

\section{๑) Copyright 2021}

Gonakoti et al. This is an open access article distributed under the terms of the Creative Commons Attribution License CC-BY 4.0., which permits unrestricted use, distribution, and reproduction in any medium, provided the original author and source are credited.
The study concluded that PEM was an independent mortality predictor for those with BP, with an increased risk of systemic complications, as well as increased healthcare utilization costs.

Categories: Internal Medicine, Infectious Disease, Pulmonology

Keywords: protein energy malnutrition (pem), respiratory bacteria, morbidity and mortality, community acquired pneumonia

\section{Introduction}

Community-acquired pneumonia (CAP) is defined as an acute infection of the lung parenchyma acquired outside of the hospital. In the United States, pneumonia accounts for over 1.2 million emergency room visits annually [1]. Risk factors for pneumonia include older age, diabetes mellitus, chronic lung diseases (e.g., asthma, chronic obstructive pulmonary disease, bronchiectasis), heart failure, smoking, and alcohol use. CAP may have bacterial or viral causes [2].

Malnutrition is a less commonly recognized risk factor for various infections. It encompasses both undernutrition or protein-energy malnutrition (PEM) and overnutrition, including obesity. Malnutrition has been reported to increase the risk of infection and impacts the hospital outcomes of various disease conditions [2-9]. The World Health Organization (WHO) estimates that 462 million adults have PEM [10]. Diagnostic criteria have been set forth by the Academy of Nutrition and Dietetics (Academy) and the American Society for Parenteral and Enteral Nutrition (ASPEN), which defines PEM as two or more of the following: insufficient energy intake, weight loss, loss of muscle mass, loss of subcutaneous fat, a localized or generalized fluid accumulation that may mask weight loss, and diminished functional status as measured by handgrip strength [11]. PEM in the adult population has been shown to increase health care utilization, with longer hospital stays and poor functional outcomes [12]. 
There is a paucity of large population-based studies on the effect of PEM on bacterial pneumonia. Hence, this study aimed to evaluate whether PEM impacts bacterial pneumonia (BP) and, if so, to quantify the degree of impact on inpatient outcomes.

\section{Materials And Methods Design and data source}

This was a retrospective cohort study involving adult hospitalizations principally for bacterial pneumonia (BP) in the US in 2016 and 2017. Data were obtained from the Nationwide Inpatient Sample (NIS) database. The NIS is a database of hospital inpatient stays derived from billing data submitted by hospitals to statewide data organizations across the US, covering more than $97 \%$ of the U.S. population [13]. It approximates a $20 \%$ stratified sample of discharges from U.S. community hospitals, excluding rehabilitation and long-term acute-care hospitals. This dataset is weighted to obtain national estimates [14]. The database was coded using the International Classification of Diseases, Tenth Revision, Clinical Modification/Procedure Coding System (ICD-10-CM/PCS). The NIS has primary and secondary diagnostic codes corresponding to the principal reason for admission and all other discharge diagnoses, respectively.

\section{Study population}

We queried the NIS 2016 and 2017 databases for patients 18 years and above who had a principal discharge diagnosis of PB. From the literature review, prior studies utilized ICD-10 codes for BP, including J13, J14, and $J 15$ [15]. This cohort was divided based on the presence of a secondary discharge diagnosis of PEM.

\section{Outcome measures}

Inpatient mortality between non-PEM and PEM with BP groups was assessed as the primary outcome. Secondary outcomes assessed included odds of sepsis, septic shock, acute hypoxic respiratory failure (ARF), acute respiratory distress syndrome (ARDS), non-ST segment elevation myocardial infarction (NSTEMI), acute kidney failure (AKI), deep vein thrombosis (DVT), pulmonary embolism (PE), cerebrovascular accident (CVA), need for mechanical ventilation, vasopressors, as well as mean length of hospital stay (LOS) and mean total hospital charges (THC).

\section{Statistical analysis}

We analyzed the data using Stata ${ }^{\circledR}$ Version 16 software (StataCorp, Texas). The proportions of comorbid diseases and baseline characteristics were compared using chi-squared tests. Multivariate regression analysis was done to adjust for possible confounders while calculating the primary and secondary outcomes. These were obtained from prior related studies reviewed and included variables from the validated pneumonia severity index [16]. A univariate screen was done to further confirm these factors affected outcomes with variables having a p-value less than 0.2 included in the multivariate analysis [17-20]. The threshold for statistical significance was 0.05 .

\section{Ethical considerations}

The NIS database lacks patient identifiers and contains only retrospective data. Hence, this study was exempt from Institutional Review Board approval.

\section{Results}

\section{Patient characteristics}

Table 1 contains patient and hospital characteristics of hospitalizations involving adults with BP. A total of 1,236,109 hospitalizations were studied. Compared to non-PEM patients, those with PEM had an older mean age $(71.8$ vs 68.4 years, $\mathrm{p}<0.001)$ with a lower proportion of women $(51.0$ vs $53.3 \%, \mathrm{p}<0.001)$. Patients with PEM had higher proportions of CKD (18.8 vs $16.9 \%$, $\mathrm{p}<0.001)$, chronic obstructive pulmonary disease (COPD) ( 37.5 vs $31.5 \%$, $\mathrm{p}<0.001$ ), and anemia ( 46.8 vs $27.1 \%$, $\mathrm{p}<0.001$ ). However, they had lower proportions of hypertension ( 36.1 vs $42.6 \%, \mathrm{p}<0.001$ ), diabetes ( 24.0 vs $31.6 \%$, $\mathrm{p}<0.001$ ), and dyslipidemia ( 31.6 vs $37.4 \%$, $\mathrm{p}<0.001)$.

\begin{tabular}{|l|l|l||}
\hline $\begin{array}{l}\text { Variable } \\
\mathrm{N}=1,236,109\end{array}$ & $\mathrm{PEM} \%$ & Without PEM \% \\
\hline $\begin{array}{l}\text { Patient characteristics } \\
\text { Age, mean years }\end{array}$ & 71.8 & $\mathrm{n}=1,149,524(93.0)$ \\
\hline $\begin{array}{l}\text { Women } \\
\text { Racial distribution }\end{array}$ & 51.0 & 68.4 \\
\hline
\end{tabular}




\section{Cureus}

\begin{tabular}{|c|c|c|c|}
\hline White & 71.0 & 71.8 & \\
\hline Black & 12.2 & 11.8 & \\
\hline Hispanic & 7.2 & 7.9 & \\
\hline Others & 9.6 & 8.5 & \\
\hline Insurance type & & & $<0.001$ \\
\hline Medicaid & 75.7 & 69.2 & \\
\hline Medicare & 10.4 & 10.9 & \\
\hline Private & 12.3 & 16.9 & \\
\hline Uninsured & 1.6 & 3.0 & \\
\hline Charlson Comorbidity Index score & & & $<0.001$ \\
\hline 0 & 10.3 & 17.3 & \\
\hline 1 & 22.0 & 25.7 & \\
\hline 2 & 19.6 & 19.5 & \\
\hline$\geq 3$ & 48.1 & 37.5 & \\
\hline Median annual income in patient's zip code, US\$\# & & & 0.013 \\
\hline $1-43,999$ & 33.4 & 33.1 & \\
\hline $44,000-55,999$ & 26.6 & 28.0 & \\
\hline $56,000-73,999$ & 22.7 & 22.1 & \\
\hline$\geq 74,000$ & 17.2 & 16.8 & \\
\hline \multicolumn{4}{|l|}{ Co-morbidities } \\
\hline Hypertension & 36.1 & 42.6 & $<0.001$ \\
\hline Diabetes & 24.0 & 31.6 & $<0.001$ \\
\hline Smoking history & 43.2 & 42.0 & 0.004 \\
\hline CHF & 25.9 & 25.0 & 0.010 \\
\hline CKD & 18.8 & 16.9 & $<0.001$ \\
\hline Dyslipidemia & 31.6 & 37.4 & $<0.001$ \\
\hline Chronic IHD & 24.4 & 25.4 & 0.004 \\
\hline Prior CVA & 3.7 & 2.6 & $<0.001$ \\
\hline COPD & 37.5 & 31.5 & $<0.001$ \\
\hline Oxygen dependent & 10.6 & 8.6 & $<0.001$ \\
\hline History of malignancy & 24.8 & 12.0 & $<0.001$ \\
\hline Anemia & 46.8 & 27.1 & $<0.001$ \\
\hline \multicolumn{4}{|l|}{ Hospital characteristics } \\
\hline Hospital region & & & $<0.001$ \\
\hline Northeast & 15.5 & 17.9 & \\
\hline Midwest & 25.1 & 24.3 & \\
\hline South & 40.1 & 41.9 & \\
\hline West & 19.3 & 15.9 & \\
\hline
\end{tabular}




\section{Cureus}

Hospital bed size

$<0.001$

Small

22.1

27.1

Medium

30.4

30.3

Large

47.5

42.6

Urban location

85.7

80.1

$<0.001$

Teaching hospital

57.1

50.9

$<0.001$

TABLE 1: Patient and hospital characteristics of hospitalizations for bacterial pneumonia by PEM

\#: for 2017. CHF: Congestive heart failure, CKD: Chronic kidney disease, COPD: Chronic obstructive pulmonary disease, CVA: Cerebrovascular accident, IHD: Ischemic heart disease, PEM: Protein-energy malnutrition

\section{Outcomes in patients with PEM}

The in-hospital mortality for adults with BP was $2.62 \%$. Patients with PEM had a higher adjusted odds ratio (aOR) of inpatient mortality (aOR: $2.31,95 \%$ confidence interval (CI): $2.14-2.48, \mathrm{p}<0.001$ ) as compared to non-PEM patients. PEM was also associated with higher odds of sepsis (aOR: 2.24, 95\% CI: $2.04-2.46$, $\mathrm{p}<0.001$ ), septic shock (aOR: $3.29,95 \%$ CI: $2.82-3.85$, p<0.001), requiring mechanical ventilation (aOR: 2.51 , 95\% CI: 2.31 - 2.71, p<0.001), requiring vasopressors (aOR: 2.90, 95\% CI: 2.20 - 3.83, p<0.001), ARDS (aOR: $1.63,95 \%$ CI: 1.33 - 2.00, p<0.001), AKI (aOR: 1.24, 95\% CI: 1.18 - 1.29, p<0.001), DVT (aOR: $1.80,95 \%$ CI: $1.62-2.00, \mathrm{p}<0.001$ ), and PE (aOR: $1.25,95 \%$ CI: $1.08-1.45$, p=0.003). Patients with PEM also had a significantly longer LOS, as well as higher THC, as compared to non-PEM patients (Table 2).

\begin{tabular}{|c|c|c|c|c|}
\hline Outcome & PEM \% & Without PEM \% & aOR $(95 \%$ Cl) & p-value ${ }^{*}$ \\
\hline $\mathrm{N}=1,236,109$ & $\mathrm{n}=86585(7.0)$ & $\mathrm{n}=1,149524(93.0)$ & & \\
\hline \multicolumn{5}{|l|}{ Primary outcome } \\
\hline In-hospital mortality & 6.8 & 2.3 & $2.31(2.14-2.48)$ & $<0.001^{*}$ \\
\hline \multicolumn{5}{|l|}{ Secondary outcomes } \\
\hline Length of stay, mean & 7.4 & 4.6 & $2.4^{\#}(2.2-2.5)$ & $<0.001^{*}$ \\
\hline Total hospital charges, mean US\$ & 63500 & 36100 & $21800^{\#}(20100-23400)$ & $<0.001^{*}$ \\
\hline Sepsis & 4.2 & 1.6 & $2.24(2.04-2.46)$ & $<0.001^{*}$ \\
\hline Septic shock & 1.5 & 0.3 & $3.29(2.82-3.85)$ & $<0.001^{*}$ \\
\hline NSTEMI & 1.6 & 1.2 & $1.10(0.96-1.26)$ & 0.158 \\
\hline Mechanically ventilated & 6.7 & 2.4 & $2.51(2.31-2.71)$ & $<0.001^{*}$ \\
\hline Used pressors & 0.5 & 0.1 & $2.90(2.20-3.83)$ & $<0.001^{*}$ \\
\hline Acute kidney failure & 20.4 & 14.9 & $1.24(1.18-1.29)$ & $<0.001^{*}$ \\
\hline Acute respiratory failure & 20.6 & 15.9 & $1.29(1.23-1.34)$ & $<0.001^{*}$ \\
\hline ARDS & 0.7 & 0.4 & $1.63(1.33-2.00)$ & $<0.001^{\star}$ \\
\hline Deep vein thrombosis & 2.8 & 1.1 & $1.80(1.62-2.00)$ & $<0.001^{*}$ \\
\hline Pulmonary embolism & 1.2 & 0.7 & $1.25(1.08-1.45)$ & $0.003^{*}$ \\
\hline Cerebrovascular accident & 0.6 & 0.3 & $1.53(1.22-1.91)$ & $<0.001^{\star}$ \\
\hline
\end{tabular}

\section{TABLE 2: Clinical outcomes in patients with bacterial pneumonia and PEM}

*; statistically significant, \#; Adjusted mean difference, aOR: Adjusted odds ratio, CI: Confidence interval, ARDS: Acute respiratory distress syndrome, NSTEMI; Non-ST segment elevation myocardial infarction, PEM: Protein-energy malnutrition 


\section{Discussion}

Risk factors for PEM in adults include age, frailty in institutionalized persons, excessive polypharmacy, general health decline, including physical function, Parkinson disease, constipation, poor or moderate selfreported health status, cognitive decline, dementia, eating dependencies, poor appetite, basal oral dysphagia, signs of impaired efficacy of swallowing, and institutionalization [21]. Synergism exists between malnutrition and infection, wherein malnutrition increases the risk of infection, and infection can lead to malnutrition. This leads to the formation of a vicious cycle. Our study reveals an increased incidence of chronic medical conditions such as chronic kidney disease, chronic obstructive pulmonary disease, and anemia in patients with PEM.

Our study demonstrated PEM as an independent mortality predictor for those with bacterial pneumonia. The estimated mortality in patients with PEM that are admitted with bacterial pneumonia is over two times higher when compared to those without PEM. Patients with PEM are at a higher risk of complications from bacterial pneumonia, including sepsis, septic shock, acute respiratory distress syndrome, acute kidney injury, deep vein thrombosis, and pulmonary embolism.

Various factors could explain the findings of this study. Malnutrition is the most common cause of secondary immunodeficiency, affecting up to $50 \%$ of at-risk populations [22]. Malnutrition affects both cell-mediated and humoral immunity. It leads to a reduction in the number of antigen-presenting-cells, such as Blymphocytes, Kupffer cells, macrophages, and dendritic cells. The complement system is also affected, limiting the phagocytic function. Severe protein-energy malnutrition in neonates and infants was associated with atrophy of bone marrow and the thymus, resulting in low B and T lymphocytes. Also, there is reduced activation of T-lymphocytes. Changes in the microanatomy of barrier epithelium also lead to an increased risk of infection [23].

Our study was based on the NIS administrative database, where the diagnosis was based on ICD-10 codes and not microbiologic confirmation, which may affect the data [24-26]. The number of patients with proteinenergy malnutrition may be underrepresented owing to under coding in an acute setting. A patient may have multiple admissions reflected in the NIS. NIS studies cannot determine causation, only potential association. These are important limitations of this study.

\section{Conclusions}

PEM is an independent mortality predictor for those with bacterial pneumonia, with an increased risk of systemic complications as well. There is a need for a multidisciplinary approach against malnutrition, which can mitigate the risk, leading to lower mortality, morbidity, and health care expenditure.

\section{Additional Information \\ Disclosures}

Human subjects: All authors have confirmed that this study did not involve human participants or tissue. Animal subjects: All authors have confirmed that this study did not involve animal subjects or tissue. Conflicts of interest: In compliance with the ICMJE uniform disclosure form, all authors declare the following: Payment/services info: All authors have declared that no financial support was received from any organization for the submitted work. Financial relationships: All authors have declared that they have no financial relationships at present or within the previous three years with any organizations that might have an interest in the submitted work. Other relationships: All authors have declared that there are no other relationships or activities that could appear to have influenced the submitted work.

\section{References}

1. National hospital ambulatory medical care survey: 2017 emergency department summary tables. (2017). https://www.cdc.gov/nchs/data/nhamcs/web_tables/2017_ed_web_tables-508.pdf.

2. Malnutrition and infection: a review. ACC/SCN state-of-the-art series . (1989). https://agris.fao.org/agrissearch/search.do?recordID=XF19900080720.

3. Iriagbonse A, Hafeez S, Edigin E, et al.: TCT CONNECT-78 Coexisting protein energy malnutrition is associated with increased mortality in patients admitted for transcatheter aortic valve replacement: analysis of the National Inpatient Sample. J Am Coll Cardiol. 2020, 76:34-35.

4. Ojemolon P, Shaka H, Edigin E, Asemota I, Akuna E: Abstract 17231: adult protein energy malnutrition is an independent risk factor with increased odds of cardiogenic shock in patients with infective endocarditis who had valve replacement. Circulation. 2020, 142:A17231. 10.1161/circ.142.suppl_3.17231

5. Shaka H, Edigin E, Gomez TMA: Obesity paradox in outcome of patients admitted with atrial fibrillation/flutter. Am Heart J. 2020, 229:159. 10.1016/j.ahj.2020.10.008

6. Shaka H, Gomez TM: Bronchogenic malignancies and the obesity paradox: adding weight to a growing argument using the nationwide inpatient sample. Chest. 2020, 158:A1470. 10.1016/j.chest.2020.08.1326

7. Shaka H, Ojemolon PE: Impact of obesity on outcomes of patients with hip osteoarthritis who underwent hip arthroplasty. Cureus. 2020, 12:e10876. 10.7759/cureus.10876

8. Shaka H, Sorto MEP, Gomez TMA, Edigin E, Xu J, Yap SE: The obesity paradox among patients hospitalized for diabetes and its complications: outcomes of the Nationwide Inpatient Sample. Diabetes. 2020, 69:242- 
LB. $10.2337 / \mathrm{db} 20-242-\mathrm{LB}$

9. Shaka H, Raghavan S, Trelles-Garcia VP, et al.: Predicting COVID-19 using retrospective data: impact of obesity on outcomes of adult patients with viral pneumonia. Cureus. 2020, 12:e10291. 10.7759/cureus.10291

10. WHO. Malnutrition. (2020). https://www.who.int/news-room/q-a-detail/malnutrition.

11. White JV, Guenter P, Jensen G, et al.: Consensus statement: Academy of Nutrition and Dietetics and American Society for Parenteral and Enteral Nutrition: characteristics recommended for the identification and documentation of adult malnutrition (undernutrition). JPEN J Parenter Enteral Nutr. 2012, 36:275-283. $10.1177 / 0148607112440285$

12. Leandro-Merhi VA, de Aquino JL, Sales Chagas JF: Nutrition status and risk factors associated with length of hospital stay for surgical patients. JPEN Journal of parenteral and enteral nutrition. 2011, 35:241-248. $10.1177 / 0148607110374477$

13. Healthcare Cost and Utilization Project. Introduction to the HCUP National Inpatient Sample (NIS) . (2020). Accessed: July 30, 2020: https://www.hcup-us.ahrq.gov/db/nation/nis/NIS_Introduction_2017.jsp.

14. Nationwide inpatient sample (NIS) redesign final report. (2014). https://www.hcupus.ahrq.gov/db/nation/nis/reports/NISRedesignFinalReport040914.pdf.

15. Shaka H, Edigin E, Raghavan S, Gomez TM: The obesity paradox among patients hospitalized for bacterial pneumonia: outcomes of the Nationwide Inpatient Sample. Chest. 2020, 158:A335. 10.1016/..chest.2020.08.332

16. Fine MJ, Auble TE, Yealy DM, et al.: A prediction rule to identify low-risk patients with community-acquired pneumonia. N Engl J Med. 1997, 336:243-250. 10.1056/nejm199701233360402

17. Edigin E, Akuna E, Asemota I, Eseaton P, Ojemolon PE, Shaka H, Manadan A: Rheumatoid arthritis does not negatively impact outcomes of patients admitted for atrial fibrillation. Cureus. 2020, 12:e10241. 10.7759/cureus. 10241

18. Edigin E, Eseaton P, Kaul S, et al.: Systemic sclerosis is not associated with worse outcomes of patients admitted for ischemic stroke: analysis of the National Inpatient Sample. Cureus. 2020, 12: e9155. 10.7759/cureus. 9155

19. Edigin E, Ojemolon PE, Eseaton PO, Shaka H, Akuna E, Asemota IR, Manadan A: Rheumatoid arthritis patients have better outcomes when hospitalized for ischemic stroke: analysis of the National Inpatient Sample. J Clin Rheumatol. 2020, [Epub ahead of print]: 10.1097/rhu.0000000000001563

20. Edigin E, Shaka $\mathrm{H}$, Eseaton $\mathrm{P}$, et al.: Rheumatoid arthritis is not associated with increased inpatient mortality in patients admitted for acute coronary syndrome. Cureus. 2020, 12:e9799. 10.7759/cureus.9799

21. Fávaro-Moreira NC, Krausch-Hofmann S, Matthys C, et al.: Risk factors for malnutrition in older adults: a systematic review of the literature based on longitudinal data. Adv Nutr. 2016, 7:507-522. 10.3945/an.115.011254

22. Geraix J, Carvalhaes M, Pereira PCM: Different nutritional-state indicators of HIV-positive individuals undergoing antiretroviral therapy. J Venom Anim Toxins incl Trop Dis. 2008, 14:338-356.

23. Redmond HP, Shou J, Kelly CJ, Schreiber S, Miller E, Leon P, Daly JM: Immunosuppressive mechanisms in protein-calorie malnutrition. Surgery. 1991, 110:311-317.

24. Ojemolon PE, Shaka H, Edigin E, et al.: Impact of diabetes mellitus on outcomes of patients with knee osteoarthritis who underwent knee arthroplasty: an analysis of the Nationwide Inpatient Sample. Cureus. 2020, 12:e8902. 10.7759/cureus.8902

25. Hafeez S, Emmanuel A, Iriagbonse A, Edigin E, Eseaton PO, Nwachukwu P, Pavon MR: Hyperthyroidism does not negatively impact the outcomes of patients admitted for atrial fibrillation: analysis of the National Inpatient Sample. Circulation. 2020, 142:16236-16236.

26. Shaka H, Asotibe JC, Achebe I, Pudasaini G: Higher inpatient morbidity and mortality in biliary pancreatitis compared to hypertriglyceridemia-induced pancreatitis: a nationwide retrospective study. Cureus. 2020, 12:e10351. 10.7759/cureus.10351 